\title{
The Nicastrin ectodomain adopts a highly thermostable structure
}

\author{
Regina Fluhrer ${ }^{1,2}$, Frits Kamp ${ }^{1}$, Gudula Grammer ${ }^{1}$, \\ Brigitte Nuscher $^{1}$, Harald Steiner ${ }^{1,2}$, Klaus Beyer ${ }^{1}$ \\ and Christian Haass ${ }^{1,2, *}$ \\ ${ }^{1}$ Adolf-Butenandt-Institute, Biochemistry, Ludwig \\ Maximilians University, Schillerstrasse 44, 80336 Munich, \\ Germany \\ ${ }^{2}$ DZNE, German Center for Neurodegenerative Diseases, \\ Schillerstrasse 44, 80336 Munich, Germany \\ * Corresponding author \\ e-mail: chaass@med.uni-muenchen.de
}

\begin{abstract}
Nicastrin is a type I transmembrane glycoprotein, which is part of the high molecular weight $\gamma$-secretase complex. $\gamma$ Secretase is one of the key players associated with the generation of Alzheimer's disease pathology, since it liberates the neurotoxic amyloid $\beta$-peptide. Four proteins Nicastrin, anterior pharynx-defective-1 (Aph-1), presenilin enhancer-2 (Pen-2) and Presenilin are essential to form the active $\gamma$ secretase complex. Recently it has been shown, that Nicastrin has a key function in stabilizing the mature $\gamma$-secretase complex and may also be involved in substrate recognition. So far no structural data for the Nicastrin ectodomain or any other $\gamma$-secretase component are available. We therefore used Circular Dichroism (CD) spectroscopy to demonstrate that Nicastrin, similar to its homologues, the Streptomyces griseus aminopeptidase (SGAP) and the transferrin receptor (TfR), adopts a thermostable secondary structure. Furthermore, the Nicastrin ectodomain has an exceptionally high propensity to refold after thermal denaturation. These findings provide evidence to further support the hypothesis that Nicastrin may share evolutionary conserved properties with the aminopeptidase and the transferrin receptor family.
\end{abstract}

Keywords: A $\beta$-peptide; Alzheimer's disease; $\gamma$-secretase; Presenilin; regulated intramembrane proteolysis (RIP); Streptomyces griseus aminopeptidase.

\section{Introduction}

Nicastrin is a 709 amino acid type I transmembrane glycoprotein, which is known to be an essential component of the $\gamma$-secretase complex (Yu et al., 2000; Edbauer et al., 2002; Leem et al., 2002; Edbauer et al., 2003). $\gamma$-Secretase cleaves a variety of substrates within the hydrophobic bilayer of cellular membranes and is a key player in the generation of the neurotoxic Amyloid $\beta$-peptide $(A \beta)$ found in neuritic plaques of Alzheimer's disease (AD) patients (Haass and Selkoe, 2007). A $\beta$ is generated via regulated intramembrane proteolysis (RIP) from the $\beta$-Amyloid Precursor Protein (APP). During amyloidogenic processing APP first undergoes shedding by the $\beta$-site APP cleaving enzyme (BACE), releasing a large part of the APP ectodomain and generating a membrane bound C-terminal stub (APP CTF). In a second proteolytic step the APP CTF is a substrate for intramembrane cleavage by $\gamma$-secretase releasing the APP intracellular domain (AICD) into the cytosol and $\mathrm{A} \beta$ into the extracellular space (Steiner et al., 2008). The active center of the $\gamma$-secretase complex is composed of either Presenilin (PS) 1 or PS2 (De Strooper et al., 1998; Steiner et al., 1999; Wolfe et al., 1999; Herreman et al., 2000; Zhang et al., 2000). PSs are nine-transmembrane proteins and belong to the GxGD-type intramembrane aspartyl proteases (Steiner et al., 2008), as one of their critical active site aspartate residues is located within a conserved GxGD-motif in transmembrane domain (TMD) 7 (Steiner et al., 2000). In addition to Nicastrin and PS two other integral membrane proteins, Aph-1 (Aph-1a or Aph-1b) and Pen-2 (Goutte et al., 2000; Francis et al., 2002), are essential to form a stable and catalytically active $\gamma$-secretase complex (Lee et al., 2002; Steiner et al., 2002; Edbauer et al., 2003; Kimberly et al., 2003; Takasugi et al., 2003). The mature $\gamma$-secretase is a stable complex with a half-life time of more than $24 \mathrm{~h}$ in mammalian cells (Ratovitski et al., 1997). During the assembly of the $\gamma$-secretase complex in the endoplasmic reticulum (ER) Nicastrin and Aph-1 form a premature subcomplex, which then recruits and stabilizes PS (LaVoie et al., 2003; Takasugi et al., 2003; Shirotani et al., 2004). Upon incorporation of Pen-2, PS is autoproteolytically cleaved within its large cytosolic loop between TMD 6 and 7 resulting in an $\mathrm{N}$ - and a C-terminal fragment, which remain tightly associated within the mature $\gamma$-secretase complex (Thinakaran et al., 1996; Capell et al., 1998; Yu et al., 2001; Takasugi et al., 2003; Prokop et al., 2004; Fukumori et al., 2010). After its complete assembly the $\gamma$ secretase complex is exported to later secretory compartments where Nicastrin undergoes complex glycosylation (Kaether et al., 2002). Nicastrin maturation in mammalian cells is dependent on the correct binding of Nicastrin to the other complex components (Edbauer et al., 2002; Kimberly et al., 2002; Leem et al., 2002; Tomita et al., 2002; Yang et al., 2002). Interestingly, complex glycosylation of Nicastrin in later secretory compartments is not necessarily required for $\gamma$-secretase activity or cell surface transport of the complex (Herreman et al., 2003; Shirotani et al., 2003). On the other hand, core glycosylation and folding of Nicas- 
trin in the ER seems to be the critical step determining stability and activity of the $\gamma$-secretase complex (Hayashi et al., 2009). Using multiple sequence alignment analysis, it has been shown that the Nicastrin ectodomain shares some homology with the aminopeptidase and transferrin receptor family. In particular, Streptomyces griseus aminopeptidase (SGAP) and the human transferrin receptor (TfR) ectodomain exhibit substantial homology with large parts of the Nicastrin ectodomain (Fagan et al., 2001). SGAP is a zincmetalloprotease, which is characterized by a high thermal stability of up to $70^{\circ} \mathrm{C}-80^{\circ} \mathrm{C}$ (Vosbeck et al., 1973). The human TfR is a type II transmembrane glycoprotein, which mediates the cellular uptake of iron by binding to and endocytosis of the serum iron transport protein transferrin (Richardson and Ponka, 1997). Like SGAP, the secondary structure of TfR exhibits an enhanced stability against thermal denaturation (Orberger et al., 2001). Due to its homology to the aminopeptidase superfamily, it was suggested that Nicastrin may serve as a substrate receptor. It was shown that Glu333 of the Nicastrin ectodomain binds to the N-termini of type I transmembrane proteins, which were truncated by the initial shedding step and serve as the immediate substrates for $\gamma$-secretase (Shah et al., 2005; Dries et al., 2009). However, these findings have been recently challenged (Chavez-Gutierrez et al., 2008; Martin et al., 2009) and it was suggested that the Nicastrin protein instead plays a critical role in stabilizing the $\gamma$-secretase complex (Zhang et al., 2005, 2010).

To provide further evidence that Nicastrin may share evolutionary conserved properties with the aminopeptidase/ transferrin receptor superfamily we investigated whether the Nicastrin ectodomain is able to adopt a characteristic and stable secondary structure with similar biophysical properties like its proposed homologues.

\section{Results}

\section{The Nicastrin ectodomain adopts a defined secondary structure}

In order to determine the structural properties and the stability of the Nicastrin ectodomain (ectoNicastrin) we expressed a Nicastrin IgG fusion protein (Figure 1A), containing the entire ectoNicastrin (amino acids 1-669) including the native $\mathrm{N}$-terminal ER targeting signal sequence in HEK293 cells. Cell lysates of HEK293 cells expressing the Nicastrin IgG fusion protein predominantly contain the immature variant of the fusion protein, while the mature form is secreted efficiently into the culture medium (Figure 1B). To ensure that Nicastrin IgG undergoes complex glycosylation similar to that of native Nicastrin, lysates and conditioned media from cells expressing endogenous Nicastrin or additionally Nicastrin $\mathrm{IgG}$ were treated with Endoglycosidase $\mathrm{H}$ (EndoH) to selectively remove non-complex sugars. The immature Nicastrin IgG found in the cell lysates was sensitive to treatment with EndoH whereas the secreted version of the fusion protein was partially resistant like the mature form of native Nicastrin [(Edbauer et al., 2002; Shi- rotani et al., 2003) and Figure 1B]. This confirms that the Nicastrin IgG fusion protein is correctly translated into the ER and undergoes complex N-glycosylation similar to endogenous Nicastrin. After demonstrating physiological maturation of Nicastrin IgG we purified the fusion protein via affinity binding to a protein A column and selectively cleaved off ectoNicastrin using Faktor Xa (Figure 1C). Factor Xa was subsequently removed using benzamidine and ectoNicastrin was further purified by size exclusion chromatography (Figure 1C). Silver staining of the respective fractions demonstrates the purity of the individual fractions (Figure 1C). To investigate whether ectoNicastrin adopts a defined secondary structure we performed Circular Dichroism (CD) spectroscopy. As indicated by the minima of the ellipticity at $210 \mathrm{~nm}$ and $222 \mathrm{~nm}$ and the maximum at $195 \mathrm{~nm}$ ectoNicastrin is predominantly in an $\alpha$-helical conformation at $20^{\circ} \mathrm{C}$ (Figure 1D). This result demonstrates that recombinant Nicastrin adopts a highly structured secondary conformation.

\section{The secondary structure of the Nicastrin ectodomain is highly thermostable}

To elucidate whether ectoNicastrin exhibits a characteristic thermostability like its potential relatives SGAP (Vosbeck et al., 1973) and TfR (Orberger et al., 2001) CD spectra were collected after stepwise heating (Figure 2). EctoNicastrin was indeed particularly stable. Upon heating only little unfolding was observed whereas the majority of ectoNicastrin remained in its predominantly $\alpha$-helical conformation up to $85^{\circ} \mathrm{C}$ (Figure 2A). Similar findings were made for the unfolding process of SGAP. SGAP lost only little of its $\alpha$ helical conformation up to $75^{\circ} \mathrm{C}$ (Figure $2 \mathrm{~B}$ ), which is consistent with previously published data (Vosbeck et al., 1973). A structural switch occurred only at temperatures above $85^{\circ} \mathrm{C}$ or $75^{\circ} \mathrm{C}$ for ectoNicastrin or SGAP, respectively, as indicated by a shift of the $\mathrm{CD}$ minimum towards $200 \mathrm{~nm}$ and the increase in CD at $222 \mathrm{~nm}$ (Figure 2A and B). At temperatures $>90^{\circ} \mathrm{C}$ SGAP started to aggregate and precipitated (data not shown). In the temperature range from $20^{\circ} \mathrm{C}$ up to $75^{\circ} \mathrm{C}$ the $\mathrm{CD}$ spectra of ectoNicastrin show an isodichroic point at $204 \mathrm{~nm}$ suggesting that there is a two state equilibrium between unfolded and folded states of the protein. In contrast, SGAP seems to undergo a gradual transition into an irreversibly denatured state, although the bulk of the protein remains folded up to $75^{\circ} \mathrm{C}$. Taken together these data suggest that the Nicastrin ectodomain acquires a highly thermostable secondary structure similar to its homologues of the aminopeptidase superfamily.

\section{The Nicastrin ectodomain refolds efficiently after thermal denaturation}

Since ectoNicastrin turned out to be extremely stable during heating, we next investigated its refolding properties. After heating to $100^{\circ} \mathrm{C}$ the sample containing ectoNicastrin was cooled to $20^{\circ} \mathrm{C}$. CD spectra were collected prior to heating, at $100^{\circ} \mathrm{C}$ and after cooling (Figure $3 \mathrm{~A}$ ). The two spectra acquired prior to heating and after cooling were highly similar and no shift of the characteristic minima was observed, 

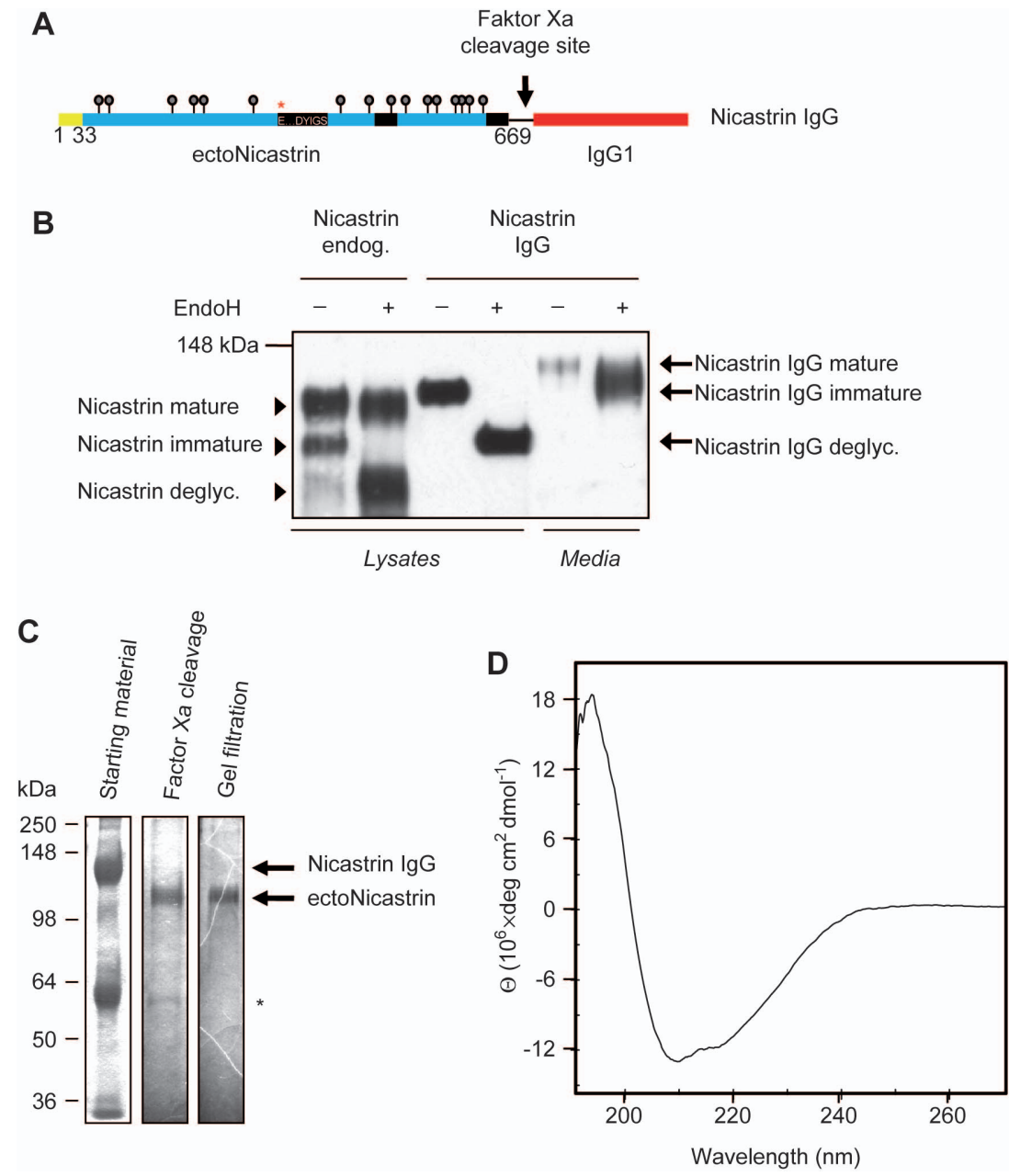

Figure 1 The Nicastrin ectodomain adopts a defined secondary structure.

(A) Model depicting the Nicastrin IgG fusion protein. The Nicastrin ectodomain is shown in blue, the IgG fusion in red and the Nicastrin signal sequence is highlighted in yellow. Black boxes indicate the conserved regions including the DYIGS (amino acid 336-340) motif and potential glycosylation sites are marked by black circles. Glu 333, which was reported to be involved in $\gamma$-secretase substrate recognition (Shah et al., 2005) is marked by an asterisk. (B) Endo H resistance of Nicastrin IgG. Immunoprecipitated endogenous Nicastrin and Nicastrin $\mathrm{IgG}$ were incubated in the presence or absence of EndoH. Nicastrin variants were detected with a polyclonal antibody directed against the N-terminus of Nicastrin. (C) Purification of ectoNicastrin. Starting material: Conditioned media from HEK293 cells, expressing the Nicastrin IgG fusion protein were separated using SDS polyacrylamid gel electrophoresis and stained with coomassie blue. Factor Xa cleavage: The starting material was applied to a Protein A column. Upon factor Xa cleavage ectoNicastrin was eluted and factor Xa was removed using a benzamidine. The eluate was separated on SDS polyacrylamid gel electrophoresis and silver-stained. Gel filtration: The concentrated benzamidine eluate was applied to a Superdex $200 \mathrm{HR}$ 30/10 gel filtration column and a silver stain of the fraction used for CD spectroscopy was performed. The asterisk indicates bovine serum albumin (BSA) from the conditioned media. (D) CD sprectroscopy of ectoNicastrin: The $\mathrm{CD}$ spectrum of ectoNicastrin was recorded at $20^{\circ} \mathrm{C}$. Note that ectoNicastrin adopts a predominantly $\alpha$-helical structure as indicated by the minima of the ellipticity $(\Theta)$ at $210 \mathrm{~nm}$ and $222 \mathrm{~nm}$ and the maximum at $195 \mathrm{~nm}$.

while the spectrum collected at $100^{\circ} \mathrm{C}$ showed a significant change in secondary structure (Figure $3 \mathrm{~A}$ ). In contrast SGAP did not regain its original structure after thermal denaturation, but rather remained in an unfolded conformation (Figure 3B). This suggests that ectoNicastrin, in contrast to SGAP, has the ability to almost completely refold to its original conformation after thermal unfolding. Taken together these data indicate that the Nicastrin ectodomain adopts a highly stable structure, which remains refoldable even upon denaturation.

\section{A $\mathrm{N}$-terminal deletion of Nicastrin reduces thermostability and the capacity of refolding}

We previously demonstrated, that deletions in the Nicastrin ectodomain abolish the incorporation of Nicastrin into the $\gamma$-secretase complex (Shirotani et al., 2003). To investigate whether such a deletion also influences the thermostability and the refolding capacity of the Nicastrin ectodomain, we expressed a Nicastrin IgG fusion protein, which lacks amino acid 40-164 of the Nicastrin ectodomain (Nicastrin IgG 

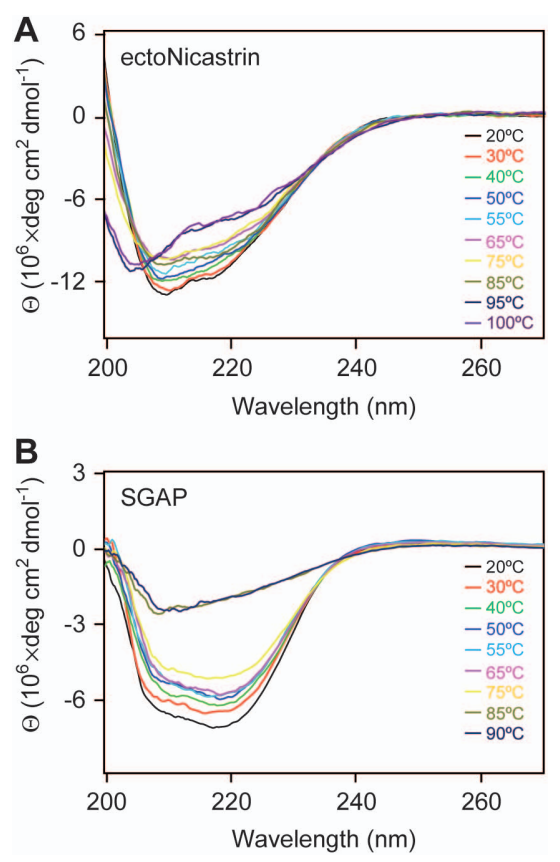

Figure 2 The ectoNicastrin secondary structure is stable up to $85^{\circ} \mathrm{C}$.

CD spectra of ectoNicastrin (A) or SGAP (B) were recorded at increasing temperatures as indicated. Both ectoNicastrin and SGAP did not significantly change their secondary structures at temperatures up to $85^{\circ} \mathrm{C}$ or $75^{\circ} \mathrm{C}$, respectively. In contrast to ectoNicastrin, which undergoes a significant structural change at temperatures $>85^{\circ} \mathrm{C}$, SGAP started to unfold at temperatures $>75^{\circ} \mathrm{C}$ and aggregated at temperatures $>90^{\circ} \mathrm{C}$.

$\Delta 40-164)$ (Figure 4A). The fusion protein was purified analogous to ectoNicastrin and the refolding capacity was determined. Compared to ectoNicastrin (Figure 3A) the refolding capacity of ectoNicastrin $\Delta 40-164$ was reduced, since the characteristic minima for an $\alpha$-helical conformation were not fully regained after sample cooling (Figure 4B). These data suggest that deletions in the ectodomain of Nicastrin might affect the thermal properties of its secondary structure.

\section{Discussion}

Here we demonstrate a surprising thermostability and refolding capacity of the recombinant Nicastrin ectodomain. This is particularly interesting since other members of the aminopeptidase family such as SGAP, which share substantial homologies with the Nicastrin ectodomain (Fagan et al., 2001) show similar properties (Vosbeck et al., 1973; Orberger et al., 2001).

Remarkably the thermostability and the capability of refolding of the Nicastrin ectodomain is even more pronounced than that of SGAP. Since recently it has been proposed, that the thermodynamic stabilization of a protein might correlate with its degree of glycosylation (Shental-Bechor and Levy, 2008), the complex glycosylation pattern within the Nicastrin ectodomain may contribute to its extraordinary thermosta- bility. The finding that a mutant variant of Nicastrin (Nicastrin $\Delta 40-164$ ) that lacks at least two glycosylation sites in the N-terminal domain shows a slightly reduced thermostability and refolding capacity, may further support this hypothesis. This idea may be additionally supported by the observation that interference with early glycosylation events in the ER causes inappropriate glycosylation of Nicastrin leading to a destabilization of the $\gamma$-secretase complex and a reduced intrinsic activity (Hayashi et al., 2009), while blocking later steps in the $\mathrm{N}$-glycosylation pathway still retains $\gamma$-secretase activity (Herreman et al., 2003; Shirotani et al., 2003). However, deletions and mutations could also affect secondary structure, thermostability and function independent of the glycosylation pattern. To finally prove the hypothesis that the degree of glycosylation within the Nicastrin ectodomain, which is determined in the ER, is responsible for stability and integrity of the $\gamma$-secretase complex, rather than the size of the polysaccharide side chains, Nicastrin mutants, which lack defined $\mathrm{N}$-glycosylation sites, should be investigated.

Although ectoNicastrin $\Delta 40-164$, according to the CD spectrum at $20^{\circ} \mathrm{C}$, seems to adopt a similar structure like ectoNicastrin this mutant variant is non-functional in a cell culture system (Shirotani et al., 2003). This suggests that
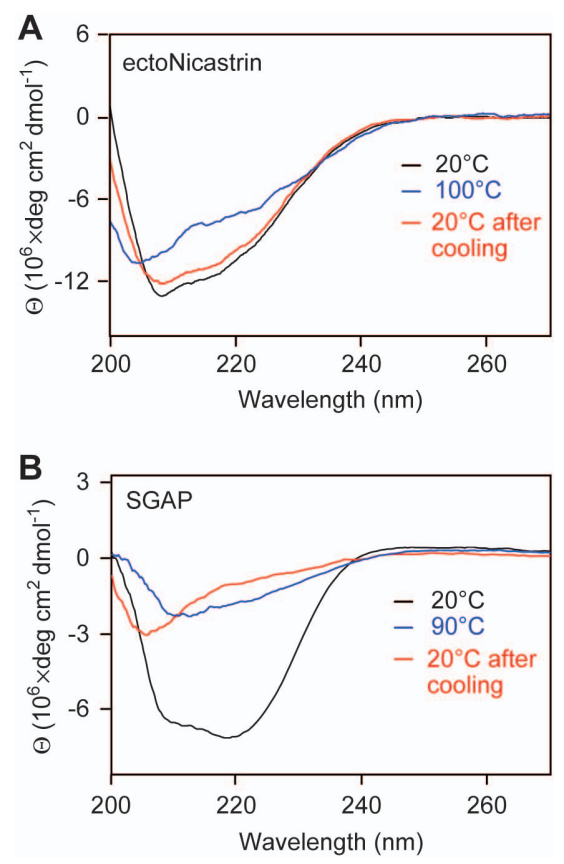

Figure 3 The ectoNicastrin refolds efficiently upon heat denaturation.

(A) The CD spectra of ectoNicastrin or (B) SGAP prior to heating were recorded at $20^{\circ} \mathrm{C}$ as described in Figure $1 \mathrm{D}$ (black line). The proteins were subsequently heated to $100^{\circ} \mathrm{C}$ (ectoNicastrin) or $90^{\circ} \mathrm{C}$ (SGAP; blue line) and cooled again followed by the recording of a third CD spectrum at $20^{\circ} \mathrm{C}$ (red line). For ectoNicastrin only a minor difference between the two spectra prior to heating and after cooling was observed, indicating that ectoNicastrin almost completely refolded after thermal unfolding. In contrast SGAP was not capable of refolding after thermal denaturation. 

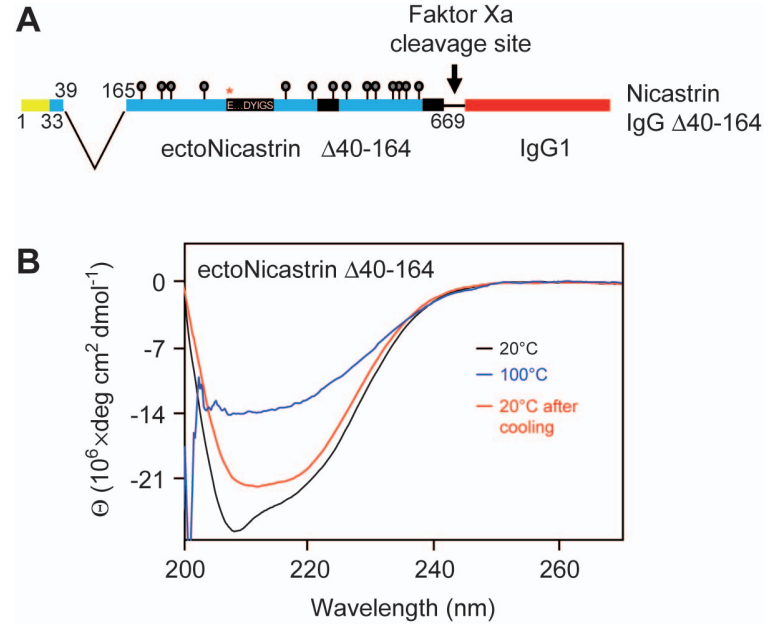

Figure 4 Reduced refolding propensities of ectoNicastrin $\Delta 40-164$.

(A) Model depicting the Nicastrin $\operatorname{IgG} \Delta 40-164$ fusion protein, which lacks amino acid 40-164 of the Nicastrin ectodomain. The mutated Nicastrin ectodomain is shown in blue, the $\operatorname{IgG}$ fusion in red and the Nicastrin signal sequence is highlighted in yellow. Black boxes indicate the conserved regions including the DYIGS (amino acid 336-340) motif and potential glycosylation sites are marked by black circles. Glu 333, which was reported to be involved in $\gamma$ secretase substrate recognition (Shah et al., 2005) is marked by an asterisk. (B) CD spectra of ectoNicastrin $\Delta 40-164$ prior to heating (black line), at $100^{\circ} \mathrm{C}$ (blue line) and after heating (red line) were recorded as described in Figure 3A. Note that in contrast to ectoNicastrin (Figure 3A) the refolding capacity of ectoNicastrin $\Delta 40-164$ is impaired, since the minima of the ellipticity $(\Theta)$ characteristic for an $\alpha$-helical conformation after heating are less pronounced than before heat denaturation.

already small changes in the secondary structure of Nicastrin are sufficient to affect the proper function of the $\gamma$-secretase complex.

Taken together, although Nicastrin lacks an aminopeptidase activity, it shows a similar extraordinary and even further improved highly thermostable secondary structure like its homologs. Whether these findings prove the hypothesis, that Nicastrin evolved from the aminopeptidase and transferrin receptor family remains, however, to be shown.

\section{Materials and methods}

\section{Cell culture, cDNAs and transfection}

HEK293EBNA cells were cultured in DMEM with Glutamax (Invitrogen $\mathrm{GmbH}$, Karlsruhe, Germany) supplemented with $10 \%$ fetal calf serum (Invitrogen $\mathrm{GmbH}$ ), and 1\% Penicillin/Streptomycin (Invitrogen $\mathrm{GmbH}$ ). Using PCR the Nicastrin ectodomain (amino acid 1-669; amino acid numbering according to $\mathrm{Yu}$ et al. (2000); GenBank: AAG11412.1) or the Nicastrin ectodomain carrying a deletion from amino acid 40-164 ( $\Delta 40-164$; amino acid numbering according to $\mathrm{Yu}$ et al. (2000); GenBank: AAG11412.1) was fused to the human IgG1 hinge-CH3 heavy chain. Between the two genes a spacer of 27 basepairs containing a Factor Xa cleavage site was included. The fusion construct was subcloned into the NheI and
NotI sites of pcDNA 3.1. Zeo - (Invitrogen GmbH), sequence verified and stably transfected into HEK293EBNA cells. Transfection of cells was carried out using Lipofectamine 2000 (Invitrogen $\mathrm{GmbH}$ ) according to the manufacturer's instructions and single cell clones were generated by selection in $200 \mu \mathrm{g} / \mathrm{ml}$ zeocine (Invitrogen $\mathrm{GmbH}$ ).

\section{Purification of the Nicastrin ectodomain (ectoNicastrin)}

Cells described above were cultured in TripleFlasks Nunclon ${ }^{\mathrm{TM}} \Delta$ Surface (Thermo Fisher Scientific, Roskilde, Denmark), conditioned medium was collected and filtered using Bottle Top Filter $0.22 \mu \mathrm{M}$ (Milipore GmbH, Schwalbach/Ts., Germany) to remove remaining cellular particles. To purify aproximatly $0.5 \mathrm{mg}$ of the Nicastrin ectodomain 51 conditioned medium were collected. The conditioned medium was directly applied to a Protein A column (GE HealthcareBio Science, Uppsala, Sweden) using an ÄKTA purifier (GE Healthcare-Bio Science) supplied with a separate sample pump (Direkt Load 960; DE Healthcare-Bio Science). After washing with $100 \mathrm{ml}$ buffer A (50 mM Tris, pH 7.4), $6 \mathrm{ml}$ Factor Xa solution [(20 mM Tris, $100 \mathrm{~mm} \mathrm{NaCl}, 2 \mathrm{~mm} \mathrm{CaCl}_{2}, \mathrm{pH} 8.0$ supplemented with $20 \mu \mathrm{g} / \mathrm{ml}$ Factor Xa (New England Biolabs, Ipswich MA, USA)] were added manually to the column and the column was incubated for roughly $16 \mathrm{~h}$ at $8^{\circ} \mathrm{C}$. To remove factor $\mathrm{Xa}$, the eluate form the Protein A column containing the cleaved Nicastrin ectodomain was directly applied to a benzamidine column (GE Healthcare-Bio Science) using $50 \mathrm{ml}$ buffer B (50 mm Tris, $500 \mathrm{~mm} \mathrm{NaCl}$, $\mathrm{pH}$ 7.4). The eluate from the benzamidine column was fractionated and the fractions containing the ectoNicastrin were pooled and concentrated to $1 / 4$ of the original volume using a Viva Spin column 50.000 MWCO (SartoriusStedim Biotech, Göttingen, Germany) according to the manufacturer's instructions. Finally the sample was applied to a Superdex 200 HR 30/10 gel filtration column (GE Healthcare-Bio Science) and separated using buffer C (20 mM sodium phosphate buffer, pH 7.2, supplemented with $100 \mathrm{mM} \mathrm{KCl}$ ).

\section{Deglycosylation experiments}

For deglycosylation cells were lysed in STEN buffer (50 mM Tris, pH 7.6, $150 \mathrm{~mm} \mathrm{NaCl}, 2$ mм EDTA) supplemented with $1 \%$ Nonidet P-40 (NP-40), $1 \%$ Triton X-100 and $2 \%$ bovine serum albumin (BSA) on ice for $20 \mathrm{~min}$. Lysates were clarified by centrifugation for $45 \mathrm{~min}$ at $100000 \mathrm{~g}$ and $4^{\circ} \mathrm{C}$. Endogenous Nicastrin was immunoprecipitated using the polyclonal antibody N1660 (SigmaAldrich, St. Louis, MO, USA) against the C-terminus of Nicastrin. Nicastrin IgG was immunoprecipitated using Protein A coupled sepharose beads (Sigma-Aldrich). Precipitates were incubated in the presence of $50 \mathrm{mU} / \mathrm{ml}$ endoglycosidase $\mathrm{H}$ (endo H; Roche Diagnostics $\mathrm{GmbH}$, Mannheim, Germany) for $14 \mathrm{~h}$ at $37^{\circ} \mathrm{C}$ in the appropriate buffer. Reactions were stopped by the addition of SDS sample buffer and reaction mixtures were separated by SDS-polyacrylamid gel electrophoresis. For Nicastrin detection the polyclonal antibody against the N-terminus of Nicastrin (NCT-NT, 1658) was used (Capell et al., 2003).

\section{Circular Dichroism (CD) spectroscopy}

Proteins were dissolved in buffer $\mathrm{C}$ (see above) at a concentration of approximately $1 \mu \mathrm{g} / \mu \mathrm{l}$ and diluted to $0.1 \mu \mathrm{g} / \mu \mathrm{l}$ with water. Aminopeptidase I from Strepomyces griseus (SGAP) was obtained from Sigma-Aldrich (Product Number A9934). CD spectra were measured with a Jasco J-810 Spectropolarimeter (Jasco, Inc., Easton MD, USA) using a cuvette with a path length of $0.2 \mathrm{~cm}$. Spectra 
of 10 scans were averaged. Temperature in the measuring cell was gradually increased as indicated in the respective figures, and at defined temperature intervals $\mathrm{CD}$ spectra were taken from $300-190 \mathrm{~nm}$. Temperature control with an accuracy of $0.5^{\circ} \mathrm{C}$ in the cuvette was achieved with a heating/cooling accessory using a Peltier element. CD data are expressed as the mean residue ellipticity $(\Theta)$ in $\operatorname{deg} \mathrm{cm}^{2} \mathrm{dmol}^{-1}$ at the respective wave length in $\mathrm{nm}$. The mean residue ellipticity was calculated from the measured ellipticity $(\theta$, in mdeg) by dividing the molar ellipticity $(\theta \times 100 /([$ Protein] $\times d)$, $\mathrm{d}$ is the cuvette path length in $\mathrm{cm}$ ) by the amount of residues $(\mathrm{N})$ of the corresponding protein ( $\mathrm{N}=675$ for EctoNicastrin; $\mathrm{N}=550$ for EctoNicastrin $\Delta 40-164 ; \mathrm{N}=284$ for SGAP). The molecular weights of EctoNicastrin and EctoNicastrin $\Delta 40-164$ were $75 \mathrm{kDa}$ and $61 \mathrm{kDa}$, respectively. The molecular weight of SGAP was $30 \mathrm{kDa}$.

\section{Acknowledgements}

This work was supported by the Leibniz Award of Deutsche Forschungsgemeinschaft (DFG; to C.H.), the Collaborative Research Center Molecular Mechanisms of Neurodegeneration (SFB 596; C.H., H.S.), the DFG grant HA1737-11-1 and HA1737-11-2 to C.H. and R.F. and the Center for Integrated Protein Science Munich. C.H. is supported by a Research Professorship provided by the $\mathrm{LMU}^{\text {excellent }}$ program. We thank Dr. Jasmin Sydow for helpful discussion, Martina Haug-Kröper and Bärbel Klier for excellent technical assistance. The cDNAs for the Nicastrin deletion construct and the human IgG heavy chain were kindly provided by Drs. Keiro Shirotani and Jürgen Haas, respectively.

\section{References}

Capell, A., Grunberg, J., Pesold, B., Diehlmann, A., Citron, M., Nixon, R., Beyreuther, K., Selkoe, D.J., and Haass, C. (1998). The proteolytic fragments of the Alzheimer's disease-associated presenilin-1 form heterodimers and occur as a $100-150-\mathrm{kDa}$ molecular mass complex. J. Biol. Chem. 273, 3205-3211.

Capell, A., Kaether, C., Edbauer, D., Shirotani, K., Merkl, S., Steiner, H., and Haass, C. (2003). Nicastrin interacts with $\gamma$-secretase complex components via the N-terminal part of its transmembrane domain. J. Biol. Chem. 278, 52519-52523.

Chavez-Gutierrez, L., Tolia, A., Maes, E., Li, T., Wong, P.C., and de Strooper, B. (2008). Glu(332) in the Nicastrin ectodomain is essential for $\gamma$-secretase complex maturation but not for its activity. J. Biol. Chem. 283, 20096-20105.

De Strooper, B., Saftig, P., Craessaerts, K., Vanderstichele, H., Guhde, G., Annaert, W., Von Figura, K., and Van Leuven, F. (1998). Deficiency of presenilin-1 inhibits the normal cleavage of amyloid precursor protein. Nature 391, 387-390.

Dries, D.R., Shah, S., Han, Y.H., Yu, C., Yu, S., Shearman, M.S., and Yu, G. (2009). Glu-333 of nicastrin directly participates in $\gamma$-secretase activity. J. Biol. Chem. 284, 29714-29724.

Edbauer, D., Winkler, E., Haass, C., and Steiner, H. (2002). Presenilin and nicastrin regulate each other and determine amyloid $\beta$ peptide production via complex formation. Proc. Natl. Acad. Sci. USA 99, 8666-8671.

Edbauer, D., Winkler, E., Regula, J.T., Pesold, B., Steiner, H., and Haass, C. (2003). Reconstitution of $\gamma$-secretase activity. Nat. Cell Biol. 5, 486-488.

Fagan, R., Swindells, M., Overington, J., and Weir, M. (2001). Nicastrin, a presenilin-interacting protein, contains an aminopeptidase/transferrin receptor superfamily domain. Trends Biochem. Sci. 26, 213-214.
Francis, R., McGrath, G., Zhang, J., Ruddy, D.A., Sym, M., Apfeld, J., Nicoll, M., Maxwell, M., Hai, B., Ellis, M.C., et al. (2002). Aph-1 and pen-2 are required for Notch pathway signaling, $\gamma$ secretase cleavage of $\beta$ APP, and presenilin protein accumulation. Dev. Cell 3, 85-97.

Fukumori, A., Fluhrer, R., Steiner, H., and Haass, C. (2010). Threeamino acid spacing of presenilin endoproteolysis suggests a general stepwise cleavage of $\gamma$-secretase-mediated intramembrane proteolysis. J. Neurosci. 30, 7853-7862.

Goutte, C., Hepler, W., Mickey, K.M., and Priess, J.R. (2000). Aph-2 encodes a novel extracellular protein required for GLP1-mediated signaling. Development 127, 2481-2492.

Haass, C. and Selkoe, D.J. (2007). Soluble protein oligomers in neurodegeneration: lessons from the Alzheimer's amyloid $\beta$-peptide. Nat. Rev. Mol. Cell Biol. 8, 101-112.

Hayashi, I., Takatori, S., Urano, Y., Iwanari, H., Isoo, N., Osawa, S., Fukuda, M.A., Kodama, T., Hamakubo, T., Li, T., et al. (2009). Single chain variable fragment against nicastrin inhibits the $\gamma$-secretase activity. J. Biol. Chem. 284, 27838-27847.

Herreman, A., Serneels, L., Annaert, W., Collen, D., Schoonjans, L., and De Strooper, B. (2000). Total inactivation of $\gamma$-secretase activity in presenilin-deficient embryonic stem cells. Nat. Cell Biol. 2, 461-462.

Herreman, A., Van Gassen, G., Bentahir, M., Nyabi, O., Craessaerts, K., Mueller, U., Annaert, W., and De Strooper, B. (2003). $\gamma$ Secretase activity requires the presenilin-dependent trafficking of nicastrin through the Golgi apparatus but not its complex glycosylation. J. Cell Sci. 116, 1127-1136.

Kaether, C., Lammich, S., Edbauer, D., Ertl, M., Rietdorf, J., Capell, A., Steiner, H., and Haass, C. (2002). Presenilin-1 affects trafficking and processing of $\beta$-APP and is targeted in a complex with nicastrin to the plasma membrane. J. Cell Biol. 158, $551-561$.

Kimberly, W.T., LaVoie, M.J., Ostaszewski, B.L., Ye, W., Wolfe, M.S., and Selkoe, D.J. (2002). Complex N-linked glycosylated nicastrin associates with active $\gamma$-secretase and undergoes tight cellular regulation. J. Biol. Chem. 277, 35113-35117.

Kimberly, W.T., LaVoie, M.J., Ostaszewski, B.L., Ye, W., Wolfe, M.S., and Selkoe, D.J. (2003). $\gamma$-Secretase is a membrane protein complex comprised of presenilin, nicastrin, Aph-1, and Pen2. Proc. Natl. Acad. Sci. USA 100, 6382-6387.

LaVoie, M.J., Fraering, P.C., Ostaszewski, B.L., Ye, W., Kimberly, W.T., Wolfe, M.S., and Selkoe, D.J. (2003). Assembly of the $\gamma$-secretase complex involves early formation of an intermediate subcomplex of Aph-1 and nicastrin. J. Biol. Chem. 278, 37213-37222.

Lee, S.F., Shah, S., Li, H., Yu, C., Han, W., and Yu, G. (2002). Mammalian APH-1 interacts with presenilin and nicastrin and is required for intramembrane proteolysis of amyloid- $\beta$ precursor protein and Notch. J. Biol. Chem. 277, 45013-45019.

Leem, J.Y., Vijayan, S., Han, P., Cai, D., Machura, M., Lopes, K.O., Veselits, M.L., Xu, H., and Thinakaran, G. (2002). Presenilin 1 is required for maturation and cell surface accumulation of nicastrin. J. Biol. Chem. 277, 19236-19240.

Martin, L., Fluhrer, R., and Haass, C. (2009). Substrate requirements for SPPL2b-dependent regulated intramembrane proteolysis. J. Biol. Chem. 284, 5662-5670.

Orberger, G., Fuchs, H., Geyer, R., Gessner, R., Kottgen, E., and Tauber, R. (2001). Structural and functional stability of the mature transferrin receptor from human placenta. Arch. Biochem. Biophys. 386, 79-88.

Prokop, S., Shirotani, K., Edbauer, D., Haass, C., and Steiner, H. (2004). Requirement of PEN-2 for stabilization of the presenilin 
$\mathrm{N}$-/C-terminal fragment heterodimer within the $\gamma$-secretase complex. J. Biol. Chem. 279, 23255-23261.

Ratovitski, T., Slunt, H.H., Thinakaran, G., Price, D.L., Sisodia, S.S., and Borchelt, D.R. (1997). Endoproteolytic processing and stabilization of wild-type and mutant presenilin. J. Biol. Chem. 272, 24536-24541.

Richardson, D.R. and Ponka, P. (1997). The molecular mechanisms of the metabolism and transport of iron in normal and neoplastic cells. Biochim. Biophys. Acta 1331, 1-40.

Shah, S., Lee, S.F., Tabuchi, K., Hao, Y.H., Yu, C., LaPlant, Q., Ball, H., Dann, C.E., 3rd, Sudhof, T., and Yu, G. (2005). Nicastrin functions as a $\gamma$-secretase-substrate receptor. Cell 122, 435-447.

Shental-Bechor, D. and Levy, Y. (2008). Effect of glycosylation on protein folding: a close look at thermodynamic stabilization. Proc. Natl. Acad. Sci. USA 105, 8256-8261.

Shirotani, K., Edbauer, D., Capell, A., Schmitz, J., Steiner, H., and Haass, C. (2003). $\gamma$-Secretase activity is associated with a conformational change of nicastrin. J. Biol. Chem. 278, 1647416477.

Shirotani, K., Edbauer, D., Kostka, M., Steiner, H., and Haass, C. (2004). Immature nicastrin stabilizes APH-1 independent of PEN-2 and presenilin: identification of nicastrin mutants that selectively interact with APH-1. J. Neurochem. 89, 1520-1527.

Steiner, H., Duff, K., Capell, A., Romig, H., Grim, M.G., Lincoln, S., Hardy, J., Yu, X., Picciano, M., Fechteler, K., et al. (1999). A loss of function mutation of presenilin-2 interferes with amyloid $\beta$-peptide production and Notch signaling. J. Biol. Chem. 274, 28669-28673.

Steiner, H., Kostka, M., Romig, H., Basset, G., Pesold, B., Hardy, J., Capell, A., Meyn, L., Grim, M.G., Baumeister, R., et al. (2000). Glycine 384 is required for presenilin-1 function and is conserved in polytopic bacterial aspartyl proteases. Nat. Cell Biol. 2, 848-851.

Steiner, H., Winkler, E., Edbauer, D., Prokop, S., Basset, G., Yamasaki, A., Kostka, M., and Haass, C. (2002). PEN-2 is an integral component of the $\gamma$-secretase complex required for coordinated expression of presenilin and nicastrin. J. Biol. Chem. 277, 39062-39065.

Steiner, H., Fluhrer, R., and Haass, C. (2008). Intramembrane proteolysis by $\gamma$-secretase. J. Biol. Chem. 283, 29627-29631.

Takasugi, N., Tomita, T., Hayashi, I., Tsuruoka, M., Niimura, M., Takahashi, Y., Thinakaran, G., and Iwatsubo, T. (2003). The role of presenilin cofactors in the $\gamma$-secretase complex. Nature 422, $438-441$.
Thinakaran, G., Borchelt, D.R., Lee, M.K., Slunt, H.H., Spitzer, L., Kim, G., Ratovitsky, T., Davenport, F., Nordstedt, C., Seeger, M., et al. (1996). Endoproteolysis of presenilin 1 and accumulation of processed derivatives in vivo. Neuron 17, 181-190.

Tomita, T., Katayama, R., Takikawa, R., and Iwatsubo, T. (2002). Complex N-glycosylated form of nicastrin is stabilized and selectively bound to presenilin fragments. FEBS Lett. 520, 117-121.

Vosbeck, K.D., Chow, K.F., and Awad, W.M., Jr. (1973). The proteolytic enzymes of the K-1 strain of Streptomyces griseus obtained from a commercial preparation (Pronase). Purification and characterization of the aminopeptidases. J. Biol. Chem. 248, 6029-6034.

Wolfe, M.S., Xia, W., Ostaszewski, B.L., Diehl, T.S., Kimberly, W.T., and Selkoe, D.J. (1999). Two transmembrane aspartates in presenilin-1 required for presenilin endoproteolysis and $\gamma$-secretase activity. Nature 398, 513-517.

Yang, D.S., Tandon, A., Chen, F., Yu, G., Yu, H., Arawaka, S., Hasegawa, H., Duthie, M., Schmidt, S.D., Ramabhadran, T.V., et al. (2002). Mature glycosylation and trafficking of nicastrin modulate its binding to presenilins. J. Biol. Chem. 277, 2813528142.

Yu, G., Nishimura, M., Arawaka, S., Levitan, D., Zhang, L., Tandon, A., Song, Y.Q., Rogaeva, E., Chen, F., Kawarai, T., et al. (2000). Nicastrin modulates presenilin-mediated notch/glp-1 signal transduction and $\beta$ APP processing. Nature 407, 48-54.

Yu, C., Kim, S.H., Ikeuchi, T., Xu, H., Gasparini, L., Wang, R., and Sisodia, S.S. (2001). Characterization of a presenilin-mediated APP carboxyl terminal fragment CTF $\gamma$ : evidence for distinct mechanisms involved in $\gamma$-secretase processing of the APP and Notch1 transmembrane domains. J. Biol. Chem. 276, 4375643760.

Zhang, Z., Nadeau, P., Song, W., Donoviel, D., Yuan, M., Bernstein, A., and Yankner, B.A. (2000). Presenilins are required for $\gamma$ secretase cleavage of $\beta \mathrm{APP}$ and transmembrane cleavage of Notch-1. Nat. Cell Biol. 2, 463-465.

Zhang, Y.W., Luo, W.J., Wang, H., Lin, P., Vetrivel, K.S., Liao, F., Li, F., Wong, P.C., Farquhar, M.G., Thinakaran, G., et al. (2005). Nicastrin is critical for stability and trafficking but not association of other presenilin $/ \gamma$-secretase components. J. Biol. Chem. 280, 17020-17026.

Zhao, G., Liu, Z., Ilagan, M.X., and Kopan, R. (2010). $\gamma$-secretase composed of PS1/Pen2/Aph1a can cleave notch and amyloid precursor protein in the absence of nicastrin. J. Neurosci. 30, $1648-1656$

Received May 30, 2011; accepted August 4, 2011 